\title{
Impact of compliance with different guidelines on physical activity during pregnancy and perceived barriers to leisure physical activity
}

\author{
Paula Clara Santos1,2, Sandra Abreu2, Carla Moreira2, Diana Lopes3, Rute Santos2,4, Odete Alves5, \\ Pedro Silva2,4, Nuno Montenegro6 \& Jorge Mota2 \\ 1Department of Physiotherapy, School of Health Technology of Porto, Polytechnic Institute of Porto, Porto, \\ Portugal, \\ 2Faculty of Sport, Research Centre in Physical Activity, Health and Leisure, University of Porto, Porto, Portugal, \\ 3Clinical Practice, Porto, Portugal, \\ 4Maia Institute of Higher Education, Maia, Portugal, \\ 5Health Unit, Alto Minho, Ponte da Barca, Portugal \\ 6Department of Obstetrics \& Gynecology, Medicine Faculty, S. João Hospital Center, University of Porto, Porto, \\ Portugal
}

\begin{abstract}
The aims of the this prospective study were to analyze physical activity (PA) engagement during the first and second trimesters, considering the different guidelines published on PA, to document the individual characteristics associated with the accomplishment of these guidelines and to examine pregnant women's perceived barriers to leisure PA, using a socioecological framework. A sample of 133 pregnant women in two stages - at 10-12 weeks' gestation (T1) and 20- 22 weeks' gestation (T2) - were evaluated. PA was assessed by accelerometry during the T1 and T2 evaluation stages.

Socio-demographic characteristics, lifestyle factors and barriers to leisure PA were assessed via questionnaire. A large proportion of women (ranging from 32\% to 96\%) did not reach the levels of PA recommended by the guidelines. There were no significant differences between $\mathrm{T} 1$ and $\mathrm{T} 2$ with regard to compliance with PA recommendations. A decrease in PA levels from T1 to T2 was noted for all recommendations. No associations were found between participants' characteristics and adherence to the recommendations in T1 and T2. No significant differences were found in barriers to leisure PA between T1 and T2. The most commonly reported barriers to leisure PA were intrapersonal, not health related. Our results indicate that there were no differences between trimesters regarding compliance of PA recommendations, and perceived barriers were similar in both trimesters.
\end{abstract}

Keywords: physical activity, pregnancy, guidelines, barriers, socioecological model

\section{Introduction}

The leading health indicators from Healthy People 2010 recommend that physical activity (PA) be one of the greatest priorities in the enhancement of women's health (Maiese, 2002). PA plays a major role in preventing such chronic diseases as hypertension, type 2 diabetes and overweight/obesity, all of which are significant risk factors for cardiovascular disease (Caperchione, Kolt, Tennent, \& Mummery, 2011; Clarke \& Gross, 2004; Haakstad \& B $\emptyset, 2011$ ). During pregnancy, PA is also associated with reduced risk of preeclampsia, gestational diabetes and preterm birth, as well as improved pain tolerance, lower total weight gain and less fat mass gain and improved self-image (Gaston \& Cramp, 2011).

For these reasons, many PA guidelines were provided. The American College of Obstetricians and Gynecologists (ACOG, 2002) encourages pregnant women without obstetric or medical problems to engage in regular PA. The Centers for Disease Control and Prevention (CDC) (Pate et al., 1995), American College of Sports Medicine (ACSM, 2006) and United States Department of Health \& Human Services (USDHHS, 2008) support ACOG's advice, although their recommended parameters for PA are somewhat different (type, duration, intensity and frequency).

Pregnancy is a life-changing event that can initiate an adverse change in PA (Borodulin, Evenson, Wen, Herring, \& Benson, 2008), and meeting PA guidelines during pregnancy can therefore be a challenge.

Some studies examining leisure PA during pregnancy have found a significant decrease in all summary measures of PA during pregnancy (Poudevigne \& O'Connor, 2006). The largest decreases have been observed in sports and leisure PA (Clarke \& Gross, 2004). Reduction of PA can have both acute implications for pregnant women (Hegaard, Pedersen, Nielsen, \& Damm, 2007; Lokey, Tran, Wells, Myer, \& Tran, 2004; Pivarnik et al., 2006) and long-term health implications (obesity, diabetes, hypertension and cardiovascular disease) for women who have been pregnant (Cramp \& Brawley, 2009; Warburton, Nicol, $\&$ Bredin, 2006). Nonetheless, we found few studies where PA patterns during pregnancy were analyzed in comparison to different PA recommendations, and so limited conclusions can be drawn about women's adherence to PA guidelines during pregnancy (Borodulin et al., 2008; Pereira et al., 2007). To understand why a large percentage of pregnant women do not engage in PA, some authors have examined the 
demographic correlates of leisure PA participation, including income (Ning et al., 2003), education (Clarke \& Gross, 2004; Evenson, Savitz, Savitz, \& Huston, 2004; Ning et al., 2003), ethnicity, marital status (Hinton \& Olson, 2001) and parity (Hegaard et al., 2011; Mottola \& Campbell, 2003; Zhang \& Savitz, 1996). The association of each of these variables and engagement in PA is inconclusive, since some studies have found a positive association and others have found a negative association or no association at all (Gaston \& Cramp, 2011). However, demographic correlates are only informative. Social cognitions may be more easily modified and, therefore, targeted for intervention. Perceived barriers to or constraints on PA are the most frequently cited correlates of physical inactivity during pregnancy (Gaston \& Cramp, 2011), although they are still not well understood (Evenson, Moos, Carrier, \& Siega-Riz, 2009) as studies of this topic have some limitations. Since pregnancy is characterised by many physical and behavioural changes, it is plausible that barriers encountered early in pregnancy might be different from those encountered in the second trimester. Thus, it may be pertinent to analyse barriers to PA during pregnancy by phase (e.g. by trimester), rather than as a whole. Besides, such barriers have sometimes been recalled retrospectively, which raises concerns about the validity of recall (Cramp \& Bray, 2009). The socioecological framework is a comprehensive, multifaceted health promotion model that takes into account the relationships among multiple factors (McLeroy, Bibeau, Steckler, \& Glanz, 1988; Sallis, Owen, \& Fisher, 2008). Thus, this model may be useful when studying barriers to PA, since interventions designed to change behaviour should consider multiple dimensions simultaneously and comprehensively (Evenson et al., 2009). It is recognised that pregnancy may be a critical period for the onset of inactivity in women (Haakstad, Voldner, Henriksen, \& BØ, 2009). The published activity guidelines of the ACOG, CDC, ACSM and USDHHS differ substantially, and it is important to understand how differences in these guidelines interfere with pregnant women's accomplishment of recommended PA levels (ACOG, 2002; ACSM, 2006; Pate et al., 1995; USDHHS, 2008). Besides, knowledge about barriers to PA may be useful when planning health promotion and preventive programs (Cramp \& Bray, 2009; Haakstad et al., 2009). Thus, the purpose of this study was to analyse PA engagement during the first and second trimesters of pregnancy, with reference to the different PA guidelines published, to document the individual characteristics associated with adherence to these guidelines and to examine pregnant women's perceived barriers to leisure PA, using a socioecological framework.

\section{Methods}

Study design and sample

This was a prospective study focused on a consecutive sample of pregnant women attending outpatient obstetrics clinics in São João Hospital in Porto, Portugal. Women were recruited and assessed when they came in for ultrasound evaluation screenings from July 2010 to May 2012. All follow-up procedures for this study were completed by September 2012.

Data were collected in two stages. The first stage was between the 10th and 12th weeks of gestation (at the time of baseline assessment) and the second was between the 20th and 22nd weeks (at the time of the second ultrasound).

All participants in this study were informed of its objectives and provided written informed consent for their participation. The study was approved by the Ethics Committee of the Hospital de São João (Reference No. 09988); it was conducted in accordance with the World Medical Association's Helsinki Declaration for Human Studies. The inclusion criteria used in this study were spontaneous pregnancy and gestational age of 10-12 weeks, as confirmed by ultrasound. Women were considered ineligible if they had severe heart disease (including symptoms of angina, myocardial infarction or arrhythmia), persistent bleeding after 12 weeks of gestation, multiple pregnancy, poorly controlled thyroid disease, pregnancy-induced hypertension or preeclampsia, diabetes or gestational diabetes (Artal \& O'Toole, 2003), an age of less than 18 or over 40 years, lack of competence in the Portuguese language or cognitive inability to answer a questionnaire (Chasan-Taber et al., 2004; Ota et al., 2008).

A total of 137 pregnant women were invited to participate in the study and 133 agreed to take part. Of those who agreed to participate, 102 and 97 completed all assessment in the first and second trimesters, respectively. The final sample, which included women who participated in both trimesters, consisted of 82 women. Pregnant women were subsequently excluded because of miscarriage $(n=1)$, no singleton pregnancy $(n=2)$ and age $(n=1)$ (Figure 1). Furthermore, the accelerometer data from 13 participants were excluded because they were lost or unusable, in some cases due to problems with their PA monitors; 17 women were excluded due to non-compliance with the requisites for analysis and 8 women dropped out. There were no significant differences in the variables tested (age, educational level, marital status, professional status, monthly income, pre-pregnancy body mass index (BMI) and parity) between the final pair sample $(\mathrm{n}=82)$ and the baseline sample $(\mathrm{n}=133)$. 


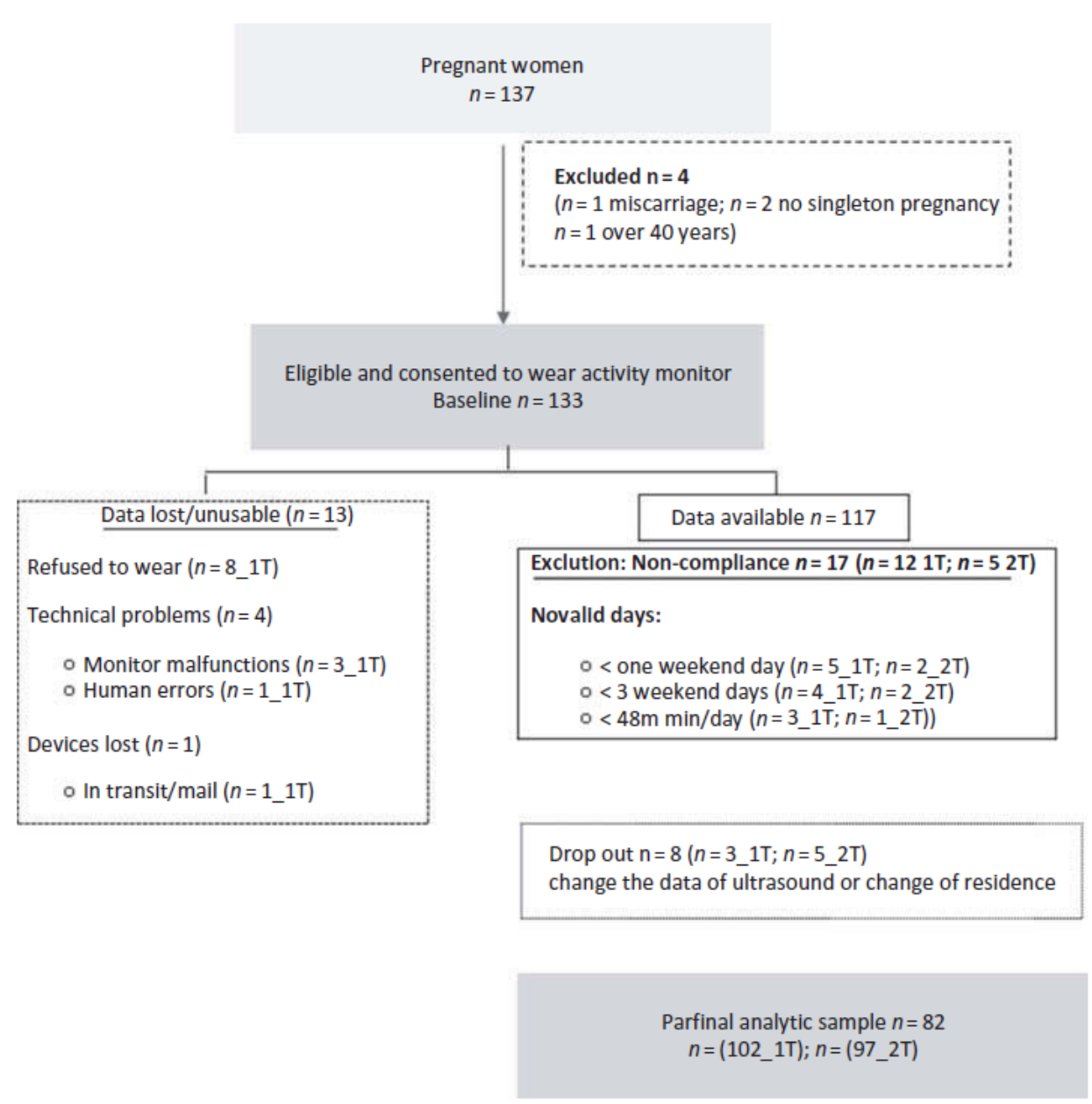

Figure 1. Flowchart of exclusions/losses and reporting physical activity monitoring results.

\section{Assessment instruments/outcome measure}

Data were collected at the time of ultrasound by researchers who administered structured and selfreported questionnaires. The questionnaires were designed to cover personal and socio-demographic data, lifestyle variables, health status during pregnancy and gynaecologic history.

Anthropometric measures. Height was measured to the nearest millimetre in bare or stocking feet, with participants standing upright against a Holtain portable stadiometer (Crymych, Pembrokeshire, UK).

Weight was measured to the nearest $0.10 \mathrm{~kg}$, with participants lightly dressed (underwear and t-shirt) and with the use of a portable digital beam scale (Tanita Inner Scan BC 532, Tokyo, Japan) Pre-pregnancy BMI was estimated from selfreported weight and height, using the formula BMI = weight $(\mathrm{kg}) / \mathrm{height} 2(\mathrm{~m} 2)$. BMI was categorized according to the Institute of Medicine (IOM, 2009) guidelines: underweight, normal weight, overweight and obese.

Socio-demographic and obstetric variables. Professional status was assessed via a self-report questionnaire, and participants were divided into three categories: employed (full-and part-time), unemployed and student. Since there were only two participants in the student category, those were pooled with members of the employed category. Respondents were asked to estimate the total income (including pensions, allowances and investments) received by all household members in the last month and to indicate this using a single measure comprised of three narrowly ranged income categories. For the variable educational level, participants were divided into three categories, reflecting the organisation of the Portuguese educational system: mandatory or less ( $\leq 9$ school years), secondary (10-12 school years) and college/university (>12 school years). Concerning number of gestations, women were considered primigest if this was their first gestation and multigest if they had at least one previous gestation.

PA measurement. The accelerometer GT3X Actigraph (ActiGraph, Pensacola, Florida, USA) was used to obtain detailed and objective information about daily PA over 7 consecutive days. This lightweight, triaxial monitor was the latest model available from the manufacturer at the time of data collection, and studies 
have demonstrated that it is a technically reliable instrument, both within and across monitors (Maddison et al., 2009). The accelerometer was attached tightly to the hip, on the right side, with the notch facing upwards, and participants were instructed to use it during waking hours and remove it during water-based activities or while sleeping, in keeping with procedures established by the manufacturer (Ward, Evenson, Vaughn, Rodgers, \& Troiano, 2005). A diary to log relevant information in wearing the device was provided. Accelerometers were setup with an epoch length set to $5 \mathrm{~s}$ to allow a more detailed estimate of PA intensity (Matthews, Hagströmer, Pober, \& Bowles, 2012). The output data were analysed by the software provided by the company (ActiLife v6.1.2, Actigraph, LLC) that provided options for screening the data and computing outcomes. Data files from individual participants were screened by detecting blocks of consecutive zeros; periods with 60 min of consecutive zeros were detected and flagged as times in which the monitor was not worn (Troiano et al., 2008). Valid days included at least 480 min of data each, and participants had to have at least four valid days to be included (three working days and one nonworking day). Nonwear time was adjusted for by averaging activity counts over the total wear time only (i.e. $24 \mathrm{~h}-$ nonwear time; Evenson \& Terry, 2009). After the screening was completed, the raw activity "counts" were processed to determine the time spent on activities of different PA intensities. Activity levels were expressed in mean counts $\cdot$ min-1. The established accelerometer cutpoints proposed by Freedson, Melanson, and Sirard (1998) were used to determine PA intensities. To verify the participant's compliance of the PA guidelines, data were processed into moderate and vigorous PA intensities. The targeted results for both intensities were accumulated during the day and not in specific bouts of time.

The pregnant women were divided into four groups, according to their adherence to PA recommendations from the ACOG (2002), CDC (Pate et al., 1995), ACSM (2006) and USDHHS 2008).

The ACOG and the CDC/ACSM suggest $30 \mathrm{~min}$ or more of moderate-intensity activity on most (5) days of the week, but they differ on type of activity, as ACOG recommends only exercise and CDC/ ACSM recommends any type of PA. The ACSM's recommendation for vigorous exercise includes any type of activity that is vigorous and is carried out at least $20 \mathrm{~min}$, three times per week. For pregnant women, USDHHS recommends $\geq 150 \mathrm{~min}$ ( $2 \mathrm{~h}$ and $30 \mathrm{~min}$ ) of moderate-intensity aerobic activity per week. We created four recommended activity levels: (1) ACOG moderate ("American College of Sports Medicine Position Stand. The recommended quantity and quality of exercise for developing and

maintaining cardiorespiratory and muscular fitness, and flexibility in healthy adults," 1998); (2) CDC moderate, (3) ACSM moderate to vigorous and (4) USDHHS moderate (Borodulin et al., 2008).

Women were considered to be engaged in leisure PA when they responded affirmatively to the question: "Currently, do you practice some form of leisure PA (like swimming, gymnastics, aerobics, cycling, walking)?"

Barriers according to the socioecological framework. All women who said that they engaged in no leisure PA in their first and second trimesters were asked about their reasons for not performing leisure PA. A table with types of barriers to leisure PA was constructed based on Evenson's study (Evenson et al., 2009); it included such possible answers as lack of time, work or social conflicts, being too busy, concern about the baby, not wanting to overdo it, medical necessity, dislike of exercise, lack of motivation, incontinence, lower back pain, pelvic pain, other medical conditions, having no one to exercise with, not having access to enough recreational facilities and not being able to afford such facilities. Participants had to indicate whether each option was considered as a barrier. Any barriers not listed in questionnaire could be listed by participants in a free-response section. The types of barriers were grouped by socioecological framework [i.e. intrapersonal (health and not health related), interpersonal, neighbourhood/ environmental and policy] (Sallis et al., 2008).

\section{Procedures}

The assessment instruments (questionnaires, anthropometric measures and accelerometer) were individually administered on ultrasound evaluation days. The women received a phone text message reminding them of how to use the accelerometer and the date of its return. The accelerometer was returned on the following week, in the hospital or by mail.

The assessment methods were common to the two evaluation moments and measured perceived barriers to leisure PA. The characterization questionnaire was applied exclusively in the first stage, and the accelerometry assessment was done in both stages (first and second trimesters).

\section{Statistics}

For statistical analysis, we used the software PASW Statistics 18 (SPSS $\odot$ IBM Corporation, Route 100) for Windows 7®. A P-value of $<0.05$ was regarded as significant. Descriptive data are presented as means and standard deviations, unless otherwise stated. Associations between variables were analyzed via statistical 
inference - specifically, using the Chisquare test or Fisher's exact test. Yates' continuity correction was used for analysis of $2 \times 2$ contingence tables. McNemar's test was used to compare paired proportions.

\section{Results}

At baseline, the mean age of participants was $30.4 \pm 5.5$ years. Almost half reported mandatory educational levels or less. Most were married or cohabitating and were employed. More than half were primigest, and $40 \%$ were overweight or obese before pregnancy (Table I).

Recommend PA levels

The proportion of women reaching ACOG's recommended level of PA during their first and second trimesters was less than 5\%. About one-third of women reached the CDC's and ACSM's PA recommendations. The USDHHS recommendations had the highest percentage of accomplishment $(68.3 \%$ and $57.3 \%$ in the first and second trimesters, respectively) (Table II).

Table I. Descriptive characteristic of sample at baseline.

\begin{tabular}{lcc}
\hline & $n$ & $n(\%)$ \\
\hline Age (years) & 133 & \\
{$[18,30]$} & & $67(50.4)$ \\
{$[31,40]$} & 132 & $66(49.6)$ \\
Educational level & & $55(41.7)$ \\
Mandatory or less & & $41(31.1)$ \\
Secondary & & $36(27.3)$ \\
College/university & 132 & \\
Marital status & & $97(73.5)$ \\
Married/cohabitating & 132 & $35(26.5)$ \\
Single/divorced & & $32(24.2)$ \\
Professional status & & \\
Employed/student & 121 & $33(27.3)$ \\
Unemployed & & $60(49.6)$ \\
Monthly income ( $)$ & & $28(23.1)$ \\
$<500$ & & $2(1.5)$ \\
[500 - 1250] & 133 & $78(58.6)$ \\
$\geq 1250$ & & $53(39.9)$ \\
Pre-pregnancy weight status & & \\
Underweight & & $56(42.1)$ \\
Normal weight & & \\
Overweight/obese & & \\
Parity & & \\
Primigest & & \\
Multigest & & \\
\hline
\end{tabular}

The percentages of women who met the PA recommendations of the ACOG, CDC, ACSM and USDHHS in both trimesters were $2.4 \%, 18.3 \%, 24.4 \%$ and $51.2 \%$, respectively. The percentages of women who did not meet these recommendations in both trimesters were $93.9 \%, 58.5 \%, 52.4 \%$ and $26.6 \%$ (data not shown).

As concerns the paired sample, there were no significant differences between first and second trimesters in compliance with the PA recommendations of the CDC, ACSM and USDHHS (P > 0.05 for all). However, 
a decrease in PA levels from the first to the second trimesters was noted for all recommendations, except the ACOG.

As regards the different PA recommendation groups, no associations were found between the participants' characteristics (socio-demographic, obstetric and behavioural) in the first and second trimesters $(\mathrm{P}>0.05$ for all, Table III).

Barriers to PA, according to the socioecological framework No statistically significant differences were found in the socioecological barriers to leisure PA between the first and second trimesters $(\mathrm{P}>0.05$ for all). The most commonly reported barrier to leisure PA in pregnancy was intrapersonal, not health related (Table IV). The non-health-related factors most frequently cited for not participating in PA were lack of time, busyness and dislike of exercise.

Table II. The definitions and proportion of pregnant woman who reached the recommended level of physical activity at 10-12 weeks (first trimester) and 20-22 weeks of gestation (second trimester) by the American College of Obstetricians and Gynecologists (ACOG), the Centers for Disease Control and Prevention (CDC) and the American College of Sports Medicine (ACSM) and United States Department of Health \& Human Services (USDHHS).

\begin{tabular}{|c|c|c|c|c|c|c|c|c|}
\hline & \multirow[b]{2}{*}{$\begin{array}{l}\text { Type of } \\
\text { activity }\end{array}$} & \multicolumn{2}{|c|}{ Definition } & \multicolumn{2}{|c|}{$\begin{array}{l}\text { Reaching recommendation } \\
\text { for total sample }[n(\%)]\end{array}$} & \multicolumn{2}{|c|}{$\begin{array}{l}\text { Reaching recommendation } \\
\text { for pairs sample }[n(\%)]\end{array}$} & \multirow[b]{2}{*}{$P^{1}$} \\
\hline & & Frequency and duration & $\begin{array}{l}\text { Intensity (Freedson } \\
\text { et al. cut-points) }\end{array}$ & $\begin{array}{l}\text { First trimester } \\
\quad n=102\end{array}$ & $\begin{array}{c}\text { Second } \\
\text { trimester } \\
n=97\end{array}$ & $\begin{array}{l}\text { First trimester } \\
\quad n=82\end{array}$ & $\begin{array}{c}\text { Second } \\
\text { trimester } \\
n=82\end{array}$ & \\
\hline ACOG & Exercise & $\begin{array}{l}\text { Accelerometry and diary } \\
\geq 5 \text { days }+30 \mathrm{~min} \\
\text { (moderate intensity) }\end{array}$ & $\begin{array}{l}\text { Moderate }(2491- \\
5944 \text { counts } / \mathrm{min})\end{array}$ & $8(7.8)$ & $8(8.2)$ & $3(3.7)$ & $4(4.9)$ & na \\
\hline $\mathrm{CDC}$ & Any & $\begin{array}{l}\geq 5 \text { days }+30 \text { min } \\
\quad \text { (moderate intensity) }\end{array}$ & $\begin{array}{l}\text { Moderate }(2491- \\
5944 \text { counts } / \mathrm{min})\end{array}$ & $34(33.3)$ & $24(24.7)$ & $28(34.1)$ & $21(25.6)$ & 0.167 \\
\hline ACSM & Any & $\begin{array}{l}\geq 5 \text { days }+30 \text { min } \\
\quad \text { (moderate intensity) } \\
\text { or }>3 \text { days }+20 \mathrm{~min} \\
\quad \text { (vigorous intensity) }\end{array}$ & $\begin{array}{l}\text { Moderate }(2491- \\
5944 \text { counts/min) } \\
\text { or vigorous } \\
(>5944 \text { counts/ } \\
\text { min) }\end{array}$ & $39(38.2)$ & $29(29.9)$ & $33(40.2)$ & $26(31.7)$ & 0.164 \\
\hline USDHHS & Any & $\begin{array}{l}\geq 150 \mathrm{~min}(2 \mathrm{~h} \text { and } \\
30 \mathrm{~min}) \text { of moderate- } \\
\text { intensity aerobic } \\
\text { activity per week }\end{array}$ & $\begin{array}{l}\text { Moderate }(2491- \\
5944 \text { counts } / \mathrm{min})\end{array}$ & $69(67.2)$ & $58(59.8)$ & $56(68.3)$ & $47(57.3)$ & 0.064 \\
\hline
\end{tabular}

Notes: na, not applicable; ${ }^{\star}$ (Freedson et al., 1998); ${ }^{1}$ Analysis by McNemar's test.

Health-related factors that were frequently mentioned included lower back pain and pelvic pain.

Interpersonal barriers to leisure PA were infrequently mentioned by participants (less than 1\%). Moreover, in the first and second trimesters, $13.3 \%$ and $10.2 \%$ of participants cited neighbourhood or environmental factors as barriers to leisure PA during pregnancy. Concerning policy barriers, less than $4 \%$ expressed concern about the costs associated with the practice of leisure PA.

\section{Discussion}

Recommended PA levels In this study, there were no significant differences between the first and second trimesters in compliance with the PA recommendations of the CDC, ACSM and USDHHS. However, a tendency for PA levels to decrease from the first to second trimesters was noticed for all recommendations. Thus, previous studies show that there is greater adherence to PA during the first trimester and a tendency for PA to decrease during pregnancy generally (Borodulin et al., 2008; Fell, Joseph, Armson, \& Dodds, 2009; Gaston \& Cramp, 2011; Poudevigne \& O'Connor, 2006; Rousham, Clarke, \& Gross, 2006). Lack of adherence to PA recommendations is mainly due to unawareness (Gouveia et al., 2007; Haakstad et al., 2009), beliefs (Duncombe, Wertheim, Skouteris, Paxton, \& Kelly, 2009; Evenson \& Bradley, 2010) and barriers (Cramp \& Bray, 2009; Evenson \& Wen, 2010; Hegaard et al., 2011). In this study, compliance with PA guidelines varied between 4\% (ACOG) and 68\% (USDHHS), depending on the type of recommendation, measurement of intensity and frequency of PA. All PA recommendations resulted in higher PA levels than the ACOG recommendation, because the ACOG recommendation only concerns exercise and thus is more restrictive. The low levels of adherence to ACOG PA recommendations may be due to the low frequency of leisure PA before becoming pregnant; in Portugal, more than $90 \%$ of women between 20 and 49 years do not exercise on a regular basis (Camões \& Lopes, 2008).

However, Borodulin et al. (2008) have estimated that the prevalence of sufficiently active women varies between 3\% (ACOG) and 38\% (ACSM). The discrepancies between Borodulin's study and ours may be due to differences in sample characteristics (the women in Borodulin's study were older and had higher 
educational levels and $71.6 \%$ were non-Hispanic whites). Furthermore, the evaluation moments were different in both studies (17-22 and 27-30 weeks in Borodulin's study; 10-12 and 20- 22 weeks in our study), as well as the methods of assessing PA levels. In the present study, PA was assessed by accelerometry, whereas in the Borodulin study, it was measured using a questionnaire. However, these two instruments have poor absolute agreement, especially in the third trimester (Harrison, Thompson, Teede, \& Lombard, 2011). 


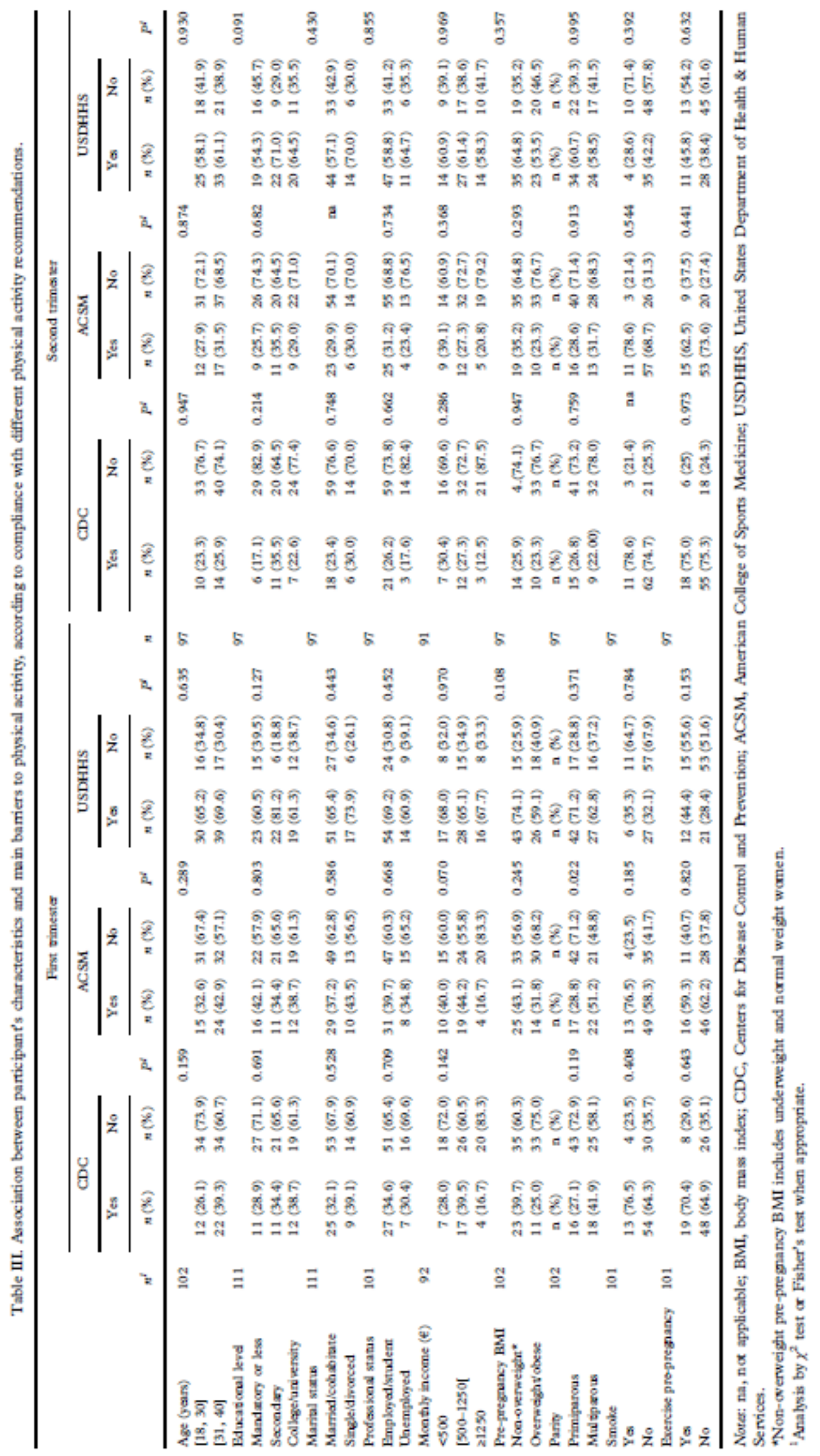


Table IV. Survey participants' main barriers to physical activity, according to the socioecological framework at 10-12 weeks (first trimester) and $20-22$ weeks of gestation (second trimester).

\begin{tabular}{|c|c|c|c|c|c|c|}
\hline \multirow[b]{2}{*}{$\begin{array}{l}\text { Barriers according to the } \\
\text { socioecologic framework }\end{array}$} & \multirow[b]{2}{*}{$\begin{array}{c}\text { Reasons for not engage in } \\
\text { leisure PA }\end{array}$} & \multicolumn{2}{|c|}{ Total sample } & \multicolumn{2}{|c|}{ Pairs sample } & \multirow[b]{2}{*}{$P^{l}$} \\
\hline & & $\begin{array}{c}\text { First trimester } \\
n=123^{\star} \\
n(\%)\end{array}$ & $\begin{array}{l}\text { Second trimester } \\
\qquad \begin{array}{c}n=105^{\star \star} \\
n(\%)\end{array}\end{array}$ & $\begin{array}{c}\text { First } \\
\text { trimester } \\
n=98\end{array}$ & $\begin{array}{c}\text { Second } \\
\text { trimester } \\
n=98\end{array}$ & \\
\hline \multicolumn{7}{|l|}{ Intrapersonal } \\
\hline \multicolumn{7}{|l|}{ Not health related } \\
\hline & $\begin{array}{l}\text { Lack of time, work or social } \\
\text { conflicts, too busy }\end{array}$ & $71(57.7)$ & $62(59.0)$ & $61(62.2)$ & $59(60.2)$ & 0.850 \\
\hline & $\begin{array}{l}\text { Concerned for the baby, does } \\
\text { not want to overdo it }\end{array}$ & $16(13.0)$ & $10(9.5)$ & $13(13.3)$ & $10(10.2)$ & 0.581 \\
\hline & Medical indication & $6(4.9)$ & $7(6.7)$ & $6(6.1)$ & $6(6.1)$ & $\mathrm{na}$ \\
\hline & Dislike exercise & $24(19.5)$ & $21(20.2)$ & $18(18.4)$ & $21(21.4)$ & 0.629 \\
\hline & Lack of motivation & $7(5.7)$ & $4(3.8)$ & $6(6.1)$ & $4(4.1)$ & 0.727 \\
\hline \multicolumn{7}{|l|}{ Health-related } \\
\hline & Lack of urine & $3(2.4)$ & $2(1.9)$ & $2(2.0)$ & $2(2.0)$ & na \\
\hline & Lower back pain & $16(13.0)$ & $11(10.5)$ & $13(13.3)$ & $10(10.2)$ & 0.648 \\
\hline & Pelvic pain & $9(7.3)$ & $12(11.4)$ & $7(7.1)$ & $11(11.2)$ & 0.554 \\
\hline & Other medical conditions & $3(2.4)$ & $1(1.0)$ & $1(1.0)$ & $0(0)$ & na \\
\hline \multicolumn{7}{|l|}{ Interpersonal } \\
\hline & No one to exercise with & $1(0.8)$ & $1(1.0)$ & $1(1.0)$ & $1(1.0)$ & $\mathrm{na}$ \\
\hline \multicolumn{7}{|c|}{ Neighbourhood or environmental } \\
\hline & $\begin{array}{l}\text { Not enough recreational } \\
\text { facilities }\end{array}$ & $17(13.8)$ & $11(10.6)$ & $13(13.3)$ & $10(10.2)$ & 0.607 \\
\hline \multicolumn{7}{|l|}{ Policy } \\
\hline & Too costly & $3(2.4)$ & $4(3.8)$ & $3(3.1)$ & $4(4.1)$ & na \\
\hline
\end{tabular}

Notes: na, not applicable. ${ }^{\star} 1 \mathrm{~T}_{-} 12$ women did leisure $\mathrm{PA} ;{ }^{\star} \star 2 \mathrm{~T}_{-} 10$ women did leisure PA; ${ }^{1}$ Analysis by McNemar's test.

Moreover, the Borodulin study did not evaluate the USDHHS PA guidelines, to which a greater number of women adhere, since these recommendations are the least demanding.

This study provides new information on the compliance with different PA recommendations among pregnant women. Pregnant women are a risk group for inactivity or reduction of PA. There is substantial evidence to show that physical inactivity is a major contributor to death and disability from noncommunicable diseases worldwide. Increasing levels of PA is one such priority (Beaglehole et al., 2011). In our sample, the application of $\mathrm{CDC} / \mathrm{ACSM} / \mathrm{USDHHS}$ definition resulted in higher percentage of guidelines accomplishment than the ACOG moderate-intensity exercise definition. Based on our results and supported by literature, we must promote the guidelines on how to recommend any type of activity (CDC/ACSM and USDHHS) and not only exercise (ACOG). Within a socioecological framework, this study also explored barriers to being active during pregnancy, the socio-demographic characteristics of inactive pregnant women and compliance with different PA guidelines. The results showed no significant association between barriers and the variables studied (age, educational level, marital status, professional status, monthly income, pre-pregnancy BMI, parity, smoking and leisure PA pre-pregnancy).

The findings of previous literature on the sociodemographic characteristics and lifestyle factors associated with PA during pregnancy have been inconsistent. According to Camões and Lopes (2008), with Portuguese pregnant women, there is a relationship between socio-demographic and behavioural factors and adherence to PA. The authors of this study reported a greater predisposition to PA in women who had higher monthly incomes and higher educational levels and were single (not married or with a partner), in contrast to women who were smokers and who were more predisposed to inactivity. Likewise, Fell et al. (2009) and (Hegaard et al., 2011) found that younger women who were nulliparous and who did not perform leisure PA before pregnancy were at higher risk of being less active. On the other hand, the findings of some other studies have been in line with the results of the present study, reporting no significant associations between PA and age (Chasan-Taber et al., 2007; Mottola \& Campbell, 2003; Watson \& McDonald, 2007), education level (Chasan-Taber et al., 2007; Clarke \& Gross, 2004), marital status (Fell et al., 2009; Mottola \& Campbell, 2003; Mudd, Nechuta, Pivarnik, \& Paneth, 2009), parity (Chasan-Taber et al., 2007; Petersen, Leet, \& Brownson, 2005), professional status (Fell et al., 2009; Pereira et al., 2007) and pre-pregnancy BMI (Chasan-Taber et al., 2007; Ning et al., 2003; Watson \& McDonald, 2007).

The present study showed no relationship between pre-pregnancy PA levels and PA during pregnancy. This finding is echoed by Hinton and Olson (2001). Nevertheless, some studies have shown that women who are 
more active prior to pregnancy remain more active during pregnancy (Chasan-Taber et al., 2007; Clarke \& Gross, 2004; Pereira et al., 2007).

Barriers to physical activity, according to the socioecological framework

In this study, according to the socioecological framework, no differences were found in barriers to leisure PA between the first and second trimesters. This is in accordance with Cramp et. al.(2009) finding that barrierswere consistent during pregnancy, except forwork. Women reported intrapersonal barriers, both nonhealth and health related, more often than they reported any other type of barrier to leisure PA during pregnancy. As regards non-health-specific reasons for lack of PA, participants referred most often to lack of time, being too busy and dislike of exercise.

A majority of the pregnant women in this study were employed and performing both professional activities and household tasks. Other studies have related that non-pregnant women only undertake PA outside of the home during daylight hours (Caperchione et al., 2011), which becomes hard with a day's work, and have also indicated that finding time to be active when not attending to family duties is a major barrier to PA engagement (Caperchione, Mummery, \& Joyner, 2009), as family duties create time conflicts. Along the same lines, Evenson et al., (2009) found that 85\% of a sample of 1535 pregnant women reported that intrapersonal factors were the main barriers to leisure PA. However, the evaluation moments in this study were different from the evaluation moments in our study (first evaluation at 20 weeks and second evaluation at 27-30 weeks).

In Rutkowska and Łepecka-Klusek (2002) study, lack of time was cited by $32 \%$ of pregnant women as a barrier to PA. Moreover, Cramp et al. (2009) reported that the proportion of women who reported work as a barrier to leisure PA was similar in the first and second trimesters.

Regarding the barrier "dislike of leisure PA", the results of the present study confirm the lesser commitment of Portuguese women to leisure PA pre-pregnancy.

Barriers related to health were third most mentioned. Only one-tenth of participants mentioned lower back pain. The findings were similar for pelvic pain, despite the high prevalence of lower back pain $-24 \%$ to 90\% (Mogren \& Pohjanen, 2005) - and pelvic pain - 4\% to 76\% - during pregnancy (Vermani, Mittal, \& Weeks, 2010). These results were not expected and indicated that the women in this study may have considered their discomfort inherent in their condition. The results, however, are in line with those of other studies (Duncombe et al., 2009; Evenson et al., 2009; Haakstad et al., 2009; Rutkowska \& Łepecka-Klusek, 2002). Interpersonal barriers to leisure PA, such as lack of support, were infrequently cited by our survey participants. This was in contradiction to our original expectations, since studies of non-pregnant women often cite social support as critical to leisure PA (Eyler et al., 2002). One explanation is that the survey participants were majority primigest $(60 \%)$, and social support in the form of childcare is frequently needed for multigest mothers. However, studies analysing the barriers to leisure PA during pregnancy are scarce. In our study, neighbourhood/environmental and policy barriers were infrequently cited as barriers to PA. Neighbourhood or environmental barriers to PA have been identified by pregnant women in other studies (Clarke \& Gross, 2004; Evenson et al., 2009), but they are typically mentioned less frequently (Clarke \& Gross, 2004).

The sample in this study was derived from a big city, and the participants might have had access to a higher number of facilities (i.e. gym) than most women in rural areas. However, big cities also have fewer leisure spaces (i.e. green space or parks) than non-urban areas. Furthermore, we should note that the study was carried out over 2 years and, for this reason, involved all seasons. In addition, Portugal has a temperate climate.

The different findings of various studies on PA during pregnancy are due mainly to the types of instruments used in these studies, as well as the characteristics of their samples. Although there was little consistency in the way that barriers were elicited (i.e. some studies used open-ended, while others used closed questionnaires), several different barriers to exercise emerged (e.g. feeling too tired, lack of time) (Gaston \& Cramp, 2011).

The strengths of our study were: (1) to our knowledge, this is the first study to measure the effects of recommended PA level on pregnancy outcomes, evaluated with objective methods (accelerometer); (2) we quantified routine PA levels of pregnant women in free-living environments; (3) this is the first study to analyze objectively compliance with different PA guidelines in a sample of Portuguese pregnant women and (4) the majority of studies on pregnancy and PA barriers have involved specific groups with comorbidities (i.e. obesity and diabetes).

There are few studies of healthy, and especially healthy pregnant, populations.

However, this study has some limitations, including the fact that Freedson's cut-points (Freedson et al., 1998), used for PA evaluation, were not specific to pregnant women, but were standardized for use with an average adult population. 
Although an open question was included in the questionnaire, to solicit mention of barriers not defined within the questionnaire, our research was still limited to the investigator's list of barriers (Duncombe et al., 2009). More studies are needed to explore the existence of other barriers.

\section{Conclusion}

There were no differences between the first and second trimesters in compliance with different PA recommendations. Individual characteristics were not associated with PA guideline accomplishment. Perceived barriers to PA were similar in both trimesters. Intrapersonal barriers were the most-often perceived barriers to leisure PA. Implications for clinical practice Healthcare professionals should use PA guidelines in their clinical practice and encourage women to follow them.

The inclusion of PA in women's lifestyles, and especially in the daily routines of pregnant women, should be encouraged in free-living environments. Thus, it is important to develop strategies to increase or maintain overall PA levels during pregnancy and daily life.

References

American College of Sports Medicine. (2006). ACSM's guidelines for exercise testing and prescription (7th ed.). Philadelphia, PA: Lippincott Williams \& Wilkins.

American College of Sports Medicine Position Stand. (1998). ACSM position stand: The recommended quantity and quality of exercise for developing and maintaining cardiorespiratory and muscular fitness, and flexibility in healthy adults. Medicine and Science in Sports and Exercise, 30(6), 975-991.

American Congress of Obstetricians and Gynecologists. (2002). ACOG committee opinion. Exercise during pregnancy and the postpartum period. Number 267, January 2002. American College of Obstetricians and Gynecologists. International Journal of Gynecology \& Obstetrics, 77(1), 79-81.

Artal, R., \& O‘Toole, M. (2003). Guidelines of the American College of Obstetricians and Gynecologists for exercise during pregnancy and the postpartum period. British Journal of Sports Medicine, 37(1), 6-12.

Beaglehole, R., Bonita, R., Horton, R., Adams, C., Alleyne, G., Asaria, P., Watt, J. (2011). Priority actions for the noncommunicable disease crisis. The Lancet, 377, 1438-1447.

Borodulin, K. M., Evenson, K. R., Wen, F., Herring, A. H., \& Benson, A. M. (2008). Physical activity patterns during pregnancy. Medicine \& Science in Sports \& Exercise, 40(11), 1901-1908.

Camões, M., \& Lopes, C. (2008). Factors associated with physical activity in the Portuguese population. Revista de Saúde Pública, $42,208-216$

Caperchione, C., Mummery, W., \& Joyner, K. (2009). Addressing the challenges, barriers and enablers to physical activity participation in priority women's groups: Findings from the WALK Program. Journal of Physical Activity \& Health, 6, 589-596.

Caperchione, C. M., Kolt, G. S., Tennent, R., \& Mummery, W.K. (2011). Physical activity behaviours of culturally and linguistically diverse (CALD) women living in Australia: A qualitative study of socio-cultural influences. BMC Public Health, 11.

Chasan-Taber, L., Schmidt, M. D., Pekow, P., Sternfeld, B., Manson, J., \& Markenson, G. (2007). Correlates of physical activity in pregnancy among Latina women. Maternal and Child Health Journal, 11(4), 353-363.

Chasan-Taber, L., Schmidt, M. D., Roberts, D. E., Hosmer, D., Markenson, G., \& Freedson, P. S. (2004). Development and validation of a pregnancy physical activity questionnaire. Medicine \& Science in Sports \& Exercise, 36(10), 1750-1760.

Clarke, P. E., \& Gross, H. (2004). Women's behaviour, beliefs and information sources about physical exercise in pregnancy. Midwifery, 20, 133-141.

Cramp, A. G., \& Brawley, L. R. (2009). Sustaining self-regulatory efficacy and psychological outcome expectations for postnatal exercise: Effects of a group-mediated cognitive behavioural intervention. British Journal of Health Psychology, 14(3), $595-611$.

Cramp, A. G., \& Bray, S. R. (2009). A prospective examination of exercise and barrier self-efficacy to engage in leisure-time physical activity during pregnancy. Annals of Behavioral Medicine, 37(3), 325-334.

Duncombe, D., Wertheim, E. H., Skouteris, H., Paxton, S. J., \& Kelly, L. (2009). Factors related to exercise over the course of pregnancy including women's beliefs about the safety of exercise during pregnancy. Midwifery, 25(4), 430-438.

Evenson, K. R., \& Bradley, C. B. (2010). Beliefs about exercise and physical activity among pregnant women. Patient Education and Counseling, 79(1), 124-129.

Evenson, K. R., Moos, M. R., Carrier, K., \& Siega-Riz, A. M. (2009). Perceived barriers to physical activity among pregnant women. Maternal and Child Health Journal, 13(3), 364-375.

Evenson, K. R., Savitz, D. A., Savitz, A., \& Huston, S. L. (2004). Leisure-time physical activity among pregnant women in the US. Paediatric and Perinatal Epidemiology, 18(6), 400-407. 
Evenson, K. R., \& Wen, F. (2010). National trends in selfreported physical activity and sedentary behaviors among pregnant women: NHANES 1999-2006. Preventive Medicine, 50(3), 123-128.

Eyler, A. E., Wilcox, S., Matson-Koffman, D., Evenson, K. R., Sanderson, B., Thompson, J., Rohm-Young, D. (2002). Correlates of physical activity among women from diverse racial/ethnic groups. Journal of Women's Health \& Gender- Based Medicine, 11(3), 239-253.

Fell, D. B., Joseph, K. S., Armson, B. A., \& Dodds, L. (2009). The impact of pregnancy on physical activity level. Maternal and Child Health Journal, 13(5), 597-603.

Freedson, P. S., Melanson, E., \& Sirard, J. (1998). Calibration of the Computer Science and Applications, Inc. accelerometer. Medicine \& Science in Sports \& Exercise, 30(5), 777-781.

Gaston, A., \& Cramp, A. (2011). Exercise during pregnancy: A review of patterns and determinants. Journal of Science and Medicine in Sport, 14, 299-305.

Gouveia, R., Martins, S., Sandes, A. R., Nascimento, C., Figueira, J., Valente, S., \& Silva, L. J. (2007). Pregnancy and physical exercise: Myths, evidence and recommendations. Acta Medica Portuguesa, 20(3), 209-214.

Haakstad, L. A., \& Bø, K. (2011). Effect of regular exercise on prevention of excessive weight gain in pregnancy: A randomized controlled trial. The European Journal of Contraception and Reproductive Health Care, 16(2), 116-125.

Haakstad, L. A., Voldner, N., Henriksen, T., \& Bø, K. (2009). Why do pregnant women stop exercising in the third trimester? Acta Obstetricia et Gynecologica Scandinavica, 88, 1267-1275.

Harrison, C. L., Thompson, R. G., Teede, H. J., \& Lombard, C. B. (2011). Measuring physical activity during pregnancy. International Journal of Behavioral Nutrition and Physical Activity, 8.

Hegaard, H. K., Damm, P., Hedegaard, M., Henriksen, T. B., Ottesen, B., Dykes, A. K., \& Kjaergaard, H. (2011). Sports and leisure time physical activity during pregnancy in nulliparous women. Maternal and Child Health Journal, 15(6), 806-813.

Hegaard, H. K., Pedersen, B. K., Nielsen, B. B., \& Damm, P. (2007). Leisure time physical activity during pregnancy and impact on gestational diabetes mellitus, pre-eclampsia, preterm delivery and birth weight: A review. Acta Obstetricia et Gynecologica Scandinavica, 86(11), 1290-1296.

Hinton, P. S., \& Olson, C. M. (2001). Predictors of pregnancyassociated change in physical activity in a rural white population. Maternal and Child Health Journal, 5(1), 7-14.

Institute of Medicine. (2009). Weight gain during pregnancy reexamining the guidelines. Washington, DC: Institute of Medicine and National Research Council.

Lokey, E., Tran, Z., Wells, C., Myer, B., \& Tran, A. (2004). Effects of physical exercise on pregnancy outcomes: A meta-analytic review. Medicine \& Science in Sports \& Exercise, 23, 1244-1251.

Maddison, R., Jiang, Y., Hoorn, S. V., Mhurchu, C. N., Lawes, C. M., Rodgers, A., \& Rush, E. (2009). Estimating energy expenditure with the RT3 triaxial accelerometer. Research Quarterly for Exercise and Sport, 80(2), 249-256.

Maiese, D. R. (2002). Healthy people 2010-leading health indicators for women. Women's Health Issues, 12(4), $155-164$.

Matthews, C. E., Hagströmer, M., Pober, D. M., \& Bowles, H. R. (2012). Best practices for using physical activity monitors in population-based research. Medicine \& Science in Sports \& Exercise, 44, SS68-SS76.

McLeroy, K. R., Bibeau, D., Steckler, A., \& Glanz, K. (1988). An ecological perspective on health promotion programs. Health Education \& Behavior, 15(4), 351-377.

Mogren, I. M., \& Pohjanen, A. I. (2005). Low back pain and pelvic pain during pregnancy: Prevalence and risk factors. Spine (Phila Pa 1976), 30(8), 983-991.

Mottola, M. F., \& Campbell, M. K. (2003). Activity patterns during pregnancy. Canadian Journal of Applied Physiology, 28 (4), 642653 .

Mudd, L. M., Nechuta, S., Pivarnik, J. M., \& Paneth, N. (2009). Factors associated with women's perceptions of physical activity safety during pregnancy. Preventive Medicine, 49, 194-199.

Ning, Y., Williams, M. A., Dempsey, J. C., Sorensen, T. K., Frederick, I. O., \& Luthy, D. A. (2003). Correlates of recreational physical activity in early pregnancy. Journal of Maternal- Fetal and Neonatal Medicine, 13(6), 385-393.

Ota, E., Haruna, M., Yanai, H., Suzuki, M., Anh, D. D., Matsuzaki, M., \& Murashima, S. (2008). Reliability and validity of the Vietnamese version of the pregnancy physical activity questionnaire (PPAQ). The Southeast Asian Journal of Tropical Medicine and Public Health, 39(3), 562-570.

Pate, R. R., Pratt, M., Blair, S. N., Haskell, W. L., Macera, C. A., Bouchard, C., Wilmore, J. H. (1995). Physical activity and public health: A recommendation from the centers for disease control and prevention and the American college of sports medicine. Journal of American Medical Association, 273(5), 402-407. 
Pereira, M. A., Rifas-Shiman, S. L., Kleinman, K. P., Rich- Edwards, J. W., Peterson, K. E., \& Gillman, M. W. (2007). Predictors of change in physical activity during and after pregnancy project viva. American Journal of Preventive Medicine, 32, $312-319$.

Petersen, A., Leet, T., \& Brownson, R. (2005). Correlates of physical activity among pregnant women in the United States. Medicine \& Science in Sports \& Exercise, 37, 1748-1753.

Pivarnik, J. M., Chambliss, H. O., Clapp, J. F., Dugan, S. A., Hatch, M. C., Lovelady, C. A., \& Williams, M. A. (2006). Impact of physical activity during pregnancy and postpartum on chronic disease risk. Medicine \& Science in Sports \& Exercise, 38(5), 9891006.

Poudevigne, M. S., \& O'Connor, P. J. (2006). A review of physical activity patterns in pregnant women and their relationship to psychological health. Sports Medicine, 36(1), 19-38

Rousham, E. K., Clarke, P. E., \& Gross, H. (2006). Significant changes in physical activity among pregnant women in the UK as assessed by accelerometry and self-reported activity. European Journal of Clinical Nutrition, 60, 393-400.

Rutkowska, E., \& Łepecka-Klusek, C. (2002). The role of physical activity in preparing women for pregnancy and delivery in Poland. Health Care for Women International, 23(8), 919-923.

Sallis, J., Owen, N., \& Fisher, E. (2008). Ecological models of health behavior. In K. Glanz, B. Rimer, \& K. Viswanath (Eds.), Health behavior and health education: Theory, research, and practice (4th ed., pp. 465-486)

San Francisco, CA: Jossey-Bass. Troiano, R. P., Berrigan, D., Dodd, K. W., MÂSSE, L. C., Tilert, T., \& McDowell, M. (2008). Physical activity in the United States measured by accelerometer. Medicine \& Science in Sports \& Exercise, 40(1), 181-188. United States Department of Health \& Human Services (USDHHS). (2008). Physical activity guidelines for Americans. Okla Nurse, 53(4), 25.

Vermani, E., Mittal, R., \& Weeks, A. (2010). Pelvic girdle pain and low back pain in pregnancy: A review. Pain Practice, $10,60-71$.

Warburton, D. E., Nicol, C. W., \& Bredin, S. S. (2006). Health benefits of physical activity: The evidence. Canadian Medical Association Journal, 174, 801-809.

Ward, D. S., Evenson, K. R., Vaughn, A., Rodgers, A. B., \& Troiano, R. P. (2005). Accelerometer use in physical activity: Best practices and research recommendations. Medicine \& Science in Sports \& Exercise, 37(Supplement), SS582-SS588.

Watson, P. E., \& McDonald, B. W. (2007). Activity levels in pregnant New Zealand women: Relationship with socioeconomic factors, well-being, anthropometricmeasures, and birth outcome. Applied Physiology, Nutrition, and Metabolism, 32(4), 733-742.

Zhang, J., \& Savitz, D. A. (1996). Exercise during pregnancy among US women. Annals of Epidemiology, 6(1), 53-59. 